\title{
A Study of Specific Down Force Energy and Cutting Depth of Sapphire Substrate Affected by Different Dipping Temperatures of Slurry
}

\author{
Zone-Ching Lin", Hao-Yang Ding, Po-Yen Chen \\ Department of Mechanical Engineering, National Taiwan University of Science and Technology, Taiwan
}

Copyright $(2017$ by authors, all rights reserved. Authors agree that this article remains permanently open access under the terms of the Creative Commons Attribution License 4.0 International License

\begin{abstract}
This article studies the change of specific down force energy and cutting depth of sapphire substrate when sapphire substrates were dipped in different temperatures of slurry. It involved applying small down force in cutting sapphire substrates by atomic force microscope (AFM) before dipping them in slurry in order to obtain the SDFE value of without dipping slurry. Next, small down force was applied to cut sapphire substrates dipped in slurry for varying dipping temperatures to obtain the $\mathrm{SDFE}_{\text {reaction }}$ values of dipping slurry with different dipping temperatures. Nanocutting was performed by AFM with a small constant down force to obtain the cutting depths of sapphire substrate for the different dipping temperatures of slurry. The results of this study indicated that the dipping temperature of slurry increased, the SDFE $_{\text {reaction }}$ value of sapphire substrate decreased and the cutting depth of sapphire substrate with a constant down force increased.
\end{abstract}

Keywords Specific Down Force Energy, Atomic Force Microscopy, Sapphire Substrate, Slurry Dipping Temperatures

\section{Introduction}

AFM is generally used for measuring and observing conductive and nonconductive surface patterns. AFM probes can be used as cutting tools and microstructures in semiconductors, optoelectronics, and metal surfaces (Tseng et al. [1]). Fang et al. [2] used AFM probes in scribing experiments involving a Si substrate coated with an Al film, and found that the scratch depth increased with the applied down force on the probe and the number of scribing cycle. The applied down force had the most notable effect. Yan et al. [3] used AFM to establish a similar cutting system based on computer numerical control. They used an AFM diamond coated probe tip as a cutting tool to scratch $\mathrm{Cu}$ film deposited on a Si substrate. Tseng et al. [4] used AFM probe tip to scratch $\mathrm{Si}$ wafer, and obtained a regression analysis that showed a logarithmic relationship between the dimension of the nanogroove and the down force of the probe, and a power-law function relationship between the dimension of the nanogroove and the number of scratching cycle. Currently, most studies on nanoscale cutting and scribing use $\mathrm{Cu}$ and $\mathrm{Al}$ as the cutting materials (Lin and Huang, [5]; Nga et al. [6]). Peng et al. [7] used AFM diamond probe to cut nanoscale groove in an Al film. Kanki et al. [8] investigated the characteristics of CMP and utilized the chemical reaction layer formed by slurry to improve the planarization of the CMP. Various slurry $\mathrm{pH}$ values, dipping times, and material electrolytic polarization characteristics were analyzed. Kanki et al. [8] also sliced $\mathrm{Cu}$ specimens dipped in slurry, and the thickness of the chemical reaction layer was determined through transmission electron microscopy. In optical semiconductor manufacturing processes, chemical mechanical polishing (CMP) is a key technology for the planarization of wafers. Factors influencing the performance of CMP include the composition, volume concentration, and temperature of the slurry, the rotation speed, down force and polishing pad. The chemical compositions in the slurry induce a chemical reaction with the material surface, generating chemical layer that are softer than the original material and easy to remove. This means that the cutting depth of each abrasive particle will be increased when sapphire substrate dipped in slurry. Therefore, this study analyzed how varying the slurry dipping temperature for sapphire substrate influenced the cutting depth and the value of specific down force.

\section{Experimental Apparatus and Method Planning}

\subsection{Experimental Apparatus and Materials}


The Dimension 3100 atomic force microscope (Veeco, Digital Instruments et al. [9]) in the Nano Lab at Tungnan University, Taiwan, was used, Sapphire substrates were used as the experimental material (diameter: $50.8 \mathrm{~mm}$ (2 in).; thickness: $0.43 \mathrm{~mm}$ ). AFM diamond coated probe was used to cut straight line groove into the sapphire substrate for observation. The sapphire substrate surface configuration was measured before and after cutting. The AFM probe used in the experiment was a DT-NCHR diamond-coated probe. The thickness of the diamond coat was approximately $100 \mathrm{~nm}$, and the semispherical tip of probe had a sphere radius of approximately $150 \mathrm{~nm}$; thus, the diamond tip of probe was used as a semispherical cutting tool during the experiment.

According to the manufacturer's instruction manual, the probe has a spring constant of $42 \mathrm{~N} / \mathrm{m}$ and a resonance frequency of $320 \mathrm{kHz}$. To obtain a more accurate spring constant $k_{r}$, it used AFM in tapping mode to perform a frequency sweep to find the actual resonance frequency $f_{r}$ of the probe. The spring constant of the probe can be expressed as $k_{r}=\left(f_{r}^{2} \times k_{v}\right) / f_{v}^{2}$. The actual spring constant $k_{r}$ of the experimental probe was calculated according to the resonance frequency $f_{v}$ and spring constant $k_{v}$ provided by the manufacturer and the measured actual resonance frequency $f_{r}$ (Lin and Hsu et al. [10]). Table 1 shows the resonance frequency and probe spring constant values used in the experiment.

In this study, the slurry was a colloidal silica suspension $(\mathrm{pH}$ 9.6, volume concentration: 50\%; Allied High Tech Products, Inc.). This slurry is suitable to use in the CMP experiment of polishing sapphire substrate.

\subsection{AFM Operation and Down Force Measurement of AFM probe}

The AFM contact mode method was employed to accurately measure the down force applied during nanoscale cutting. The force-distance curve method was adopted to measure the applied down force of the probe on the cutted workpiece. The force-distance curve depicts the relationship between the setpoint and the offset of the probe cantilever. In the force calibration mode, the setpoint is the horizontal center of the force-distance curve. The setpoint can be set to obtain the cantilever offset $d$ of the probe under down force. The down force $F_{d}$ can be obtained using the following equation:

$$
F_{d}=k_{r} d \text {. }
$$

To determine the relationship between the setpoint and the down force of the AFM probe applied on sapphire substrate, prior to conducting the experiment, the different setpoints were set with the AFM contact mode. The cantilever offset $d$ at each setpoint was substituted into Equation (1) to obtain the corresponding down force value.

\subsection{Dipping Temperature Control Method in Experiment}

As for dipping temperature control, first of all, slurry is poured to a beaker, which is then placed on a heating plate. Adjust the button on the heating device to different numerical figures in order to acquire the slurry temperatures required by the study, i.e. $30^{\circ} \mathrm{C}, 40^{\circ} \mathrm{C}$ and $50^{\circ} \mathrm{C}$, as well as room temperature $23^{\circ} \mathrm{C}$. In the heating process of slurry, thermometer is used to monitor the temperature. Once the slurry is heated to a specific temperature, the slurry is poured to another beaker, and sapphire substrate is dipped in the heated slurry for 60 minutes. Once the slurry temperature starts to fall, another beaker is used to hold the slurry on the heating plate, and then the slurry is poured to the beaker dipped with sapphire substrate. In the meantime, thermometer is used to monitor the slurry temperature. Through the ways of pouring in the heated slurry and measuring temperature by thermometer, the temperature of slurry is controlled at the required temperature of $\pm 1^{\circ} \mathrm{C}$, meeting the requirement of the experimental parameter of temperature.

\subsection{Experimental Planning}

First, the sapphire substrate was dipped in the slurry for $60 \mathrm{~min}$ at the various dipping temperatures of $23^{\circ} \mathrm{C}, 30^{\circ} \mathrm{C}$, $40^{\circ} \mathrm{C}, 50^{\circ} \mathrm{C}$. The probe of AFM is used as a tool to cut the sapphire substrate with a down force, then the cutting depths and removed volumes of the sapphire substrate at different slurry dipping temperatures can be obtained. The equation of specific down force energy was used to obtain the values of SDFE without dipping slurry and $\mathrm{SDFE}_{\text {reaction }}$ at the various dipping temperatures of slurry. Finally, a small constant down force of AFM is used to cut the sapphire substrate to obtain the cutting depths of sapphire substrate at the various dipping temperatures of slurry.

Table 1. Resonance frequency and probe spring constant used in the experiment

\begin{tabular}{|c|c|c|c|}
\hline$f_{r}$ (measured resonance frequency) & $385 \mathrm{kHz}$ & $k_{r}$ (actual probe spring constant) & $60.8 \mathrm{~N} / \mathrm{m}$ \\
\hline$f_{v}$ (manufacturer-provided resonance frequency) & $320 \mathrm{kHz}$ & $k_{v}$ (manufacturer-provided probe spring constant) & $42.0 \mathrm{~N} / \mathrm{m}$ \\
\hline
\end{tabular}




\section{SDFE Theoretical Model and Calculation Method}

The study considered that during the actual nanocutting process, down force is applied when the probe exerts sufficient downward force to achieve a certain depth in the workpiece for cutting in the cutting direction. The specific down force energy, SDFE, is defined as following equation (2) (Lin and Hsu et al. [9]):

$$
\mathrm{SDFE}=\frac{F_{d} \times \Delta d_{n}}{\Delta V_{n}}
$$

where $F_{d}$ is the down force exerted by the probe tool, $\Delta d_{n}$ is the increase in cutting depth for cutting pass $n$, and $\Delta V_{n}$ is the volume removed from the workpiece for cutting pass $n$. Because the change in volume is relative to the increase in cutting depth, $\Delta V_{n}$ is a function of $\Delta d_{n}$.

In this study, it assumed that with the same workpiece material, the SDFE would be relatively constant. Additionally, because the probe tip was a semispherical cutting tool, the volume removed from the workpiece during the first cutting pass was determined using a geometric formula for spheres. Grooves were created in each cutting pass by pressing the semispherical cutting tool into the workpiece in a linear motion. Observation of the groove configuration after the cutting experiment indicated that the probe tool initially penetrated the workpiece at a shallow depth; as the probe tool moved to an intermediate region, the cutting depth increased to a fixed value, thus increasing the removal volume. Therefore, to ensure that the cutting depth was in line with actual machining conditions, the average cutting depth was measured and calculated based on the intermediate region of the groove.

As mentioned, the volume of material removed on the first cutting pass was the volume of a spherical cap initially. At this point, the down-force removed volume is the volume of the spherical cap of the probe tip. The depth gradually became fixed after the tool was moved to the intermediate region of the cutted groove. Of the volume removed by the applied down force of the moving probe tip, the volume with a distance of radius $R$ behind the spherical cap of the probe tip penetrating the workpiece in a forward direction was removed. At this time, the removed volume was half of the spherical cap volume and is expressed as follows:

$$
V_{1}=\frac{1}{2} \pi d_{1}^{2}\left(R-\frac{d_{1}}{3}\right)
$$

where $R$ is the probe tip radius of the cutting tool, and $d_{1}$ is the cutting depth during the first cutting pass. CATIA computer-aided design (CAD) software also can be used to establish solid models of the geometric shape in order to calculate removed volume and cutting depth.

In the study, a fixed down force was applied to the workpiece. The radius of the probe tip and the cutting depth were used to calculate the workpiece volume removed during the first cutting pass. CAD software also can be used to simulate and calculate the workpiece volume removed and cutting depth. The SDFE value was obtained by multiplying the down force with the cutting depth and dividing it by the removed volume, as expressed in Equation (2).

\section{The SDFE Value of Sapphire Substrate}

\subsection{The SDFE Value of Sapphire Substrate without Dipping Slurry}

Table 2 shows the related AFM experimental data for the first cutting pass of the sapphire substrate without slurry dipping under various levels of down force and at room temperature $\left(23^{\circ} \mathrm{C}\right)$. The results in Table 2 were input into the CAD software to calculate the volume removed at that depth. When SDFE equation was input into the calculation, it found that the SDFE values tended to approach the constant value of $0.1827 \mu \mathrm{N} \cdot \mathrm{nm} / \mathrm{nm}^{3}$.

Table 2. AFM experimental data from the first cutting pass of straight-ling groove cutting of sapphire substrate without dipping in slurry at various levels of down force

\begin{tabular}{|c|c|c|c|c|}
\hline down force $(\mu \mathrm{N})$ & $\begin{array}{c}\text { measured cutting depth of } \\
\text { the first cutting pass }(\mathrm{nm})\end{array}$ & $\begin{array}{c}\text { removed volume obtained by CAD } \\
\text { calculation }\left(\mathrm{nm}^{3}\right)\end{array}$ & $\begin{array}{c}\text { removed volume calculated by } \\
\left.\text { theoretical equation }(\mathrm{nm})^{3}\right)\end{array}$ & $\begin{array}{c}\text { SDFE value calculated by } \\
\text { theoretical equation } \\
\left(\mu \mathrm{N} \cdot \mathrm{nm}^{3} / \mathrm{nm}^{3}\right)\end{array}$ \\
\hline 32.67 & 0.951 & 169.71 & 205.24 & 0.1828 \\
\hline 35.93 & 1.045 & 205.24 & 288.37 \\
\hline 42.46 & 1.239 & 288.37 & 383.39 \\
\hline 49.10 & 1.429 & 383.39 & 0.1827 \\
\hline
\end{tabular}




\subsection{The SDFE Value of Sapphire Substrate Dipped in Different Temperatures of Slurry}

The experimental parameters were the various dipping temperatures $\left(23^{\circ} \mathrm{C}, 30^{\circ} \mathrm{C}, 40^{\circ} \mathrm{C}\right.$ and $\left.50^{\circ} \mathrm{C}\right)$, the dipping time (60 $\mathrm{min})$, and the volume concentration of the slurry (50\%). After dipping the sapphire substrate in slurry with dipping temperature, it applied a small down force for AFM nanoscale cutting of $\mathrm{V}$-shaped groove to obtain the cutting depth and SDFE value of the chemical reaction layer of the slurry-dipped sapphire substrate. Initially, small down force was applied in the nanoscale cutting to ensure that the cutting depth would not exceed the thickness of the chemical reaction layer. Tables 3 and 4 show the results of dipping the sapphire substrate in slurry at temperatures of $23^{\circ} \mathrm{C}$ and $50^{\circ} \mathrm{C}$ for dipping time of $60 \mathrm{~min}$ respectively. An AFM probe tip with radius of $150 \mathrm{~nm}$ was used for the experiment. A small down force was applied to cut the sapphire substrate to obtain the value of $\mathrm{SDFE}_{\text {reaction }}$ of different dipping temperatures of slurry. The term $\Delta d_{z}$ denotes the cutting depth and $\Delta V$ is the removed volume. Tables 3 and 4 show that when the sapphire substrate was dipped in slurry for $60 \mathrm{~min}$ at dipping temperatures of $23^{\circ} \mathrm{C}$ and $50^{\circ} \mathrm{C}$ (slurry volume concentration: $50 \%$ ), the average SDFE value of the chemical reaction layer (i.e., average $\mathrm{SDFE}_{\text {reaction }}$ value) were $0.1622 \mu \mathrm{N} \cdot \mathrm{nm} / \mathrm{nm}^{3}$ (dipping temperature: $23{ }^{\circ} \mathrm{C}$ ) and $0.1516 \mu \mathrm{N} \cdot \mathrm{nm} / \mathrm{nm}^{3}$ (dipping temperature: $50^{\circ} \mathrm{C}$ ), respectively. Using the above mentioned experimental method, this steady also obtained the average values of SDFE reaction of the chemical reaction layer of the sapphire substrate at the dipping slurry temperatures of $30^{\circ} \mathrm{C}$ and $40^{\circ} \mathrm{C}$. They were average $\mathrm{SDFE}_{\text {reaction }}$ value of $0.1597 \mu \mathrm{N} \cdot \mathrm{nm} / \mathrm{nm}^{3}$ (dipping slurry temperature: $30^{\circ} \mathrm{C}$ ) and

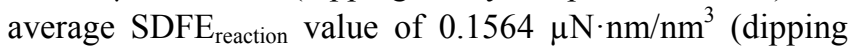
slurry temperature: $40^{\circ} \mathrm{C}$ ), respectively.

\subsection{Verify the Calculation Cutting Depth by Using Equation of SDFE with the Experimental Result}

This study used down force $4.21 \mathrm{uN}$ to take an experiment of AFM and obtained the cutting depth of sapphire substrate dipped in slurry for dipping temperature $50^{\circ} \mathrm{C}$ was $0.118 \mathrm{~nm}$. Then, it used equation of $\mathrm{SDFE}_{\text {reaction }}$ with value of $\operatorname{SDFE}_{\text {reaction }}\left(0.1516\left(\mu \mathrm{N} \cdot \mathrm{nm} / \mathrm{nm}^{3}\right)\right)$ for dipping temperature $50^{\circ} \mathrm{C}$ to calculate the cutting depth of sapphire substrate for dipping slurry temperature of $50^{\circ} \mathrm{C}$. The obtained calculation cutting depth is $0.1179 \mathrm{~nm}$. These two cutting depths are very closed. Therefore, it verifies that the equation of $\mathrm{SDFE}_{\text {reaction }}$ is acceptable and can be used to calculate the cutting depth of sapphire substrate dipping in different temperatures of slurry.

Table 3. Down force, cutting depth, removed volume, and $\mathrm{SDFE}_{\text {reaction }}$ value of AFM experiment on a sapphire substrate dipped in slurry for 60 min (slurry volume concentration: $50 \%$; dipping slurry temperature: $23^{\circ} \mathrm{C}$ )

\begin{tabular}{|c|c|c|c|c|}
\hline $\begin{array}{l}\text { down force } \\
F_{d}(\mu N)\end{array}$ & $\begin{array}{l}\text { cutting depth } \Delta d_{z} \\
(\mathrm{~nm})\end{array}$ & $\begin{array}{c}\text { removed volume } \\
\Delta V\left(\mathrm{~nm}^{3}\right)\end{array}$ & $\begin{array}{c}\text { SDFE }_{\text {reaction Value }} \\
\left(\mu \mathrm{N} \cdot \mathrm{nm} / \mathrm{nm}^{3}\right)\end{array}$ & cutting width (nm) \\
\hline 2.14 & 0.056 & 0.7388 & 0.162207 & 8.181 \\
\hline 2.16 & 0.057 & 0.7521 & 0.162274 & 8.202 \\
\hline & \multicolumn{2}{|c|}{ Average $\mathrm{SDFE}_{\text {reaction }}$ value } & 0.1622 & \\
\hline
\end{tabular}

Table 4. Down force, cutting depth, removed volume, and $\mathrm{SDFE}_{\text {reaction }}$ value of AFM experiment on a sapphire substrate dipped in slurry for 60 min (slurry volume concentration: $50 \%$; dipping slurry temperature: $50^{\circ} \mathrm{C}$ ).

\begin{tabular}{|c|c|c|c|c|}
\hline $\begin{array}{c}\text { down force } \mathrm{F}_{\mathrm{d}} \\
(\mu \mathrm{N})\end{array}$ & $\begin{array}{c}\text { cutting depth } \Delta d_{z} \\
(\mathrm{~nm})\end{array}$ & $\begin{array}{c}\text { removed volume } \\
\Delta V\left(\mathrm{~nm}^{3}\right)\end{array}$ & $\begin{array}{c}\mathrm{SDFE}_{\text {reaction value }} \\
\left(\mu \mathrm{N} \cdot \mathrm{nm} / \mathrm{nm}^{3}\right)\end{array}$ & $\begin{array}{c}\text { cutting width } \\
(\mathrm{nm})\end{array}$ \\
\hline 2.04 & 0.057 & 0.7654 & 0.151621 & 8.27 \\
\hline 2.11 & 0.059 & 0.8201 & 0.151621 & 8.413 \\
\hline 2.21 & 0.062 & 0.9056 & 0.151622 & 8.625 \\
\hline 4.11 & 0.115 & 3.1153 & 0.151621 & 11.745 \\
\hline \multicolumn{2}{r}{ Average $\mathrm{SDFE}_{\text {reaction }}$ value } \\
\hline
\end{tabular}




\section{Results}

This study obtained experimental data at various dipping temperatures $\left(23^{\circ} \mathrm{C} 、 30^{\circ} \mathrm{C} 、 40^{\circ} \mathrm{C} 、 50^{\circ} \mathrm{C}\right)$. The $\mathrm{SDFE}_{\text {reaction }}$ values of sapphire substrate for various slurry dipping temperatures obtained from the AFM experimental results and SDFE equation were different. This is because the change of the slurry dipping temperature may change the bonding energy of the chemical reaction layer of sapphire substrate. It also may make sapphire substrate softer and become easy to cut. According to above mentioned experimental results that the $\mathrm{SDFE}_{\text {reaction }}$ values for dipping slurry temperatures of $23{ }^{\circ} \mathrm{C}, 30{ }^{\circ} \mathrm{C}, 40{ }^{\circ} \mathrm{C}, 50{ }^{\circ} \mathrm{C}$ are $0.1622 \mu \mathrm{N} \cdot \mathrm{nm} / \mathrm{nm}^{3}, 0.1597 \mu \mathrm{N} \cdot \mathrm{nm} / \mathrm{nm}^{3}, 0.1564 \mu \mathrm{N} \cdot \mathrm{nm} / \mathrm{nm}^{3}$ and $0.1516 \mu \mathrm{N} \cdot \mathrm{nm} / \mathrm{nm}^{3}$, respectively. It can be found that the dipping slurry temperatures increased, the values of $\mathrm{SDFE}_{\text {reaction }}$ decreased.

Then, a small constant down force of $3.0 \mu \mathrm{N}$ is used to substitute into equation of SDFEreaction (Eguation(2)) to obtain the cutting depths of sapphire substrate for dipping slurry temperatures of $23^{\circ} \mathrm{C}, 30^{\circ} \mathrm{C}, 40^{\circ} \mathrm{C}$ and $50^{\circ} \mathrm{C}$. The cutting depths for dipping slurry temperatures of $23^{\circ} \mathrm{C}, 30^{\circ} \mathrm{C}$, $40^{\circ} \mathrm{C}$ and $50^{\circ} \mathrm{C}$ obtained by equation of $\mathrm{SDFE}_{\text {reaction }}$ are $0.0785 \mathrm{~nm}, \quad 0.0797 \mathrm{~nm}, \quad 0.0814 \mathrm{~nm}, \quad$ and $0.0840 \mathrm{~nm}$, respectively. It can be found that the dipping slurry temperatures increased, the cutting depths increased. These two phenomena concerning the dipping slurry temperatures

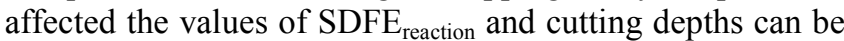
shown in Fig. 1 and Fig.2.

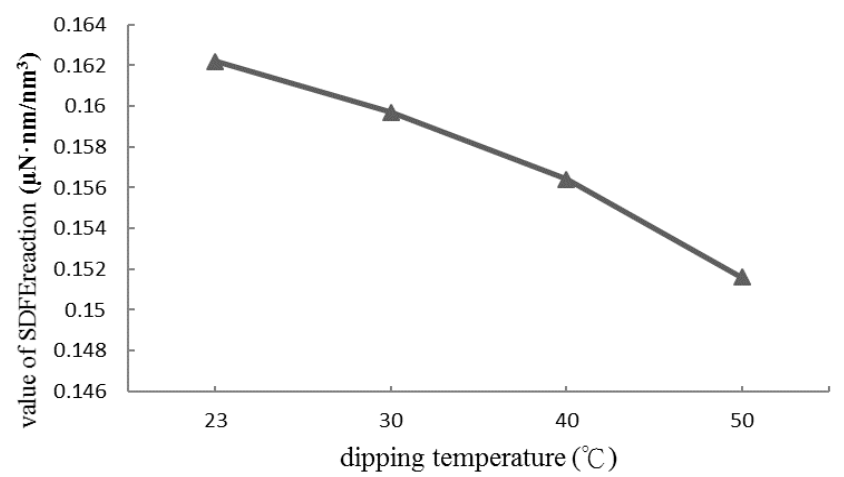

Figure 1. The diagram of tendency between value of $\mathrm{SDFE}_{\text {reaction }}$ and dipping temperatures of slurry

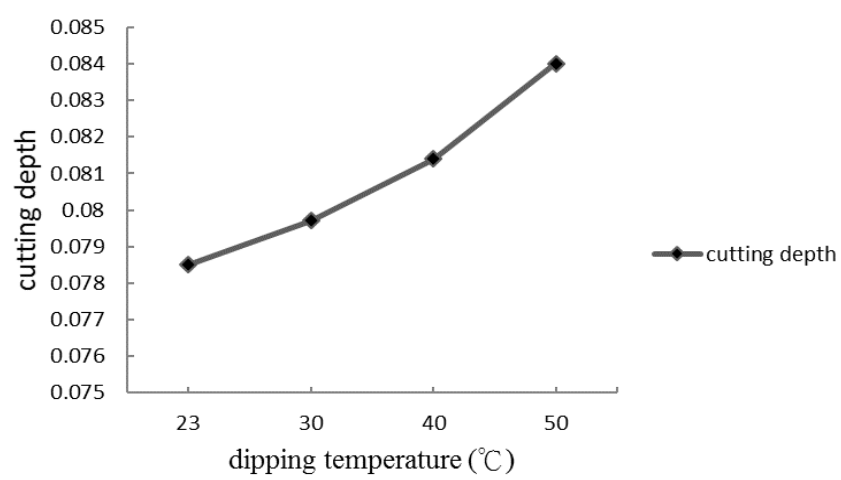

Figure 2. The diagram of tendency between cutting depth and dipping temperature of slurry

\section{Conclusions}

In optical semiconductor manufacturing processes, chemical mechanical polishing (CMP) is a key technology for the planarization of wafers. Factors influencing the performance of CMP include the composition, volume concentration, and temperature of the slurry, the rotation speed, down force and polishing pad. Thus the temperature of slurry is an important factor affected the performance of CMP. This paper studies the change of specific down force energy and cutting depth of sapphire substrate when sapphire substrates were dipped in different temperatures of slurry. It involved applying small down force in cutting sapphire substrates by atomic force microscope (AFM) before dipping them in slurry in order to obtain the SDFE value of without dipping slurry. Next, small down force was applied to cut sapphire substrates dipped in slurry for verying dipping temperatures to obtain the $\mathrm{SDFE}_{\text {reaction }}$ values of dipping slurry with different dipping temperatures. Nanocutting was performed by AFM with a small constant down force to obtain the cutting depths of sapphire substrate for the different dipping temperatures of slurry. The results indicated that the dipping temperature of slurry increased, the $\mathrm{SDFE}_{\text {reaction }}$ value of sapphire substrate decreased, and the cutting depth of sapphire substrate with a constant down force increased. This also means that cutting depth of each abrasive particle of CMP will be increased when temperature of slurry increased.

\section{Acknowledgements}

The authors would like to thank the support from Ministry of Science and Technology, Taiwan, (grant number MOST 105-2221-E-011-001).

\section{REFERENCES}

[1] Tseng, A. A., Jou, S., Notargiacomo, A. \& Chen, T. P.(2008). Recent developments in tip-based nanofabrication and its roadmap, Journal of Nanoscience \& Nanotechnology, 8(5), $2167-2186$.

[2] Fang, T. H., Weng, C. I. \& Chang, J. G. (2000). Machining characterization of nano-lithography process by using atomic force microscopy, Nanotechnology, 11(5), 181-187.

[3] Yan, Y., Sun, T., Liang, Y. C., \& Dong, S. (2007). Investigation on AFM based micro/nano CNC machining system. International Journal of Machine Tools and Manufacture, 47(11), 1651-1659.

[4] Tseng, A. A. (2010). A comparison study of scratch and wear properties using atomic force microscopy. J. Applied Surface Science, 256(13), 4246- 4252.

[5] Lin, Z. C. \& Huang, J. C. (2008). The study of estimation method of cutting force for conical tool under nanoscale depth 
of cut by molecular dynamics. Nanotechnology, 19, 115701-1 $\sim 115701-13$.

[6] Nga, C. K., Melkotea, S. N., Rahmanb, M., \& Kumar, A. S. (2006). Experimental study of micro- and nano-scale cutting of aluminum 7075-T6. Machine Tools \& Manufacture, 46(9), 929-936.

[7] Peng, P., Shi, T., Liao, G., Tang, Z., \& Liu, C. (2009). Scratch of submicron grooves on aluminum film with AFM diamond tip. IEEE International Conference on Nano/Micro Engineered and Molecular Systems, Shenzhen, China, 983-986.
[8] Kanki, T., Kimura, T., \& Nakamura T. (2013). Chemical and mechanical properties of cu surface reaction layers in cu CMP to improve planarization. ECS Journal of Solid State Science and Technology, 2(9), 375-379.

[9] .Digital Instruments, Dimension ${ }^{\mathrm{TM}} 3100$ Manual. Version 4.43B, (2000). Digital Instruments Veeco Metrilogy Group.

[10] Lin, Z. C. \& Hsu, Y. C.(2012). A study of estimating cutting depth for multi- Pass nanoscale cutting by using atomic force microscopy. J. Appl. Surf. Sci, 258, 4513-4522. 